\title{
Significance of hydrogen sulfide in sepsis-induced myocardial injury in rats
}

\author{
XIAOQING LI ${ }^{1}$, QINGHONG CHENG ${ }^{2}$, JIANHUA LI ${ }^{2}$, YONGLAI HE ${ }^{2}$, PEIGANG TIAN $^{2}$ and CHAO XU ${ }^{2}$ \\ ${ }^{1}$ Department of Critical Care Medicine, School of Medicine, Shihezi University; ${ }^{2}$ Department of Critical Care Medicine, \\ First Affiliated Hospital, School of Medicine, Shihezi University, Shihezi, Xinjiang 832003, P.R. China
}

Received December 8, 2016; Accepted May 2, 2017

DOI: $10.3892 / \mathrm{etm} .2017 .4742$

\begin{abstract}
Sepsis-induced myocardial injury is a detrimental disorder for intensive care medicine due to its high rates of morbidity and mortality. Data suggest that nuclear factor $(\mathrm{NF})-\kappa \mathrm{B}$ serves a critical role in the pathogenesis of myocardial injury. Hydrogen sulfide $\left(\mathrm{H}_{2} \mathrm{~S}\right)$ serves an important role in the physiology and pathophysiology of regulatory mechanisms, particularly during an inflammatory reaction. However, the relationship between $\mathrm{NF}-\kappa \mathrm{B}$ and $\mathrm{H}_{2} \mathrm{~S}$ in sepsis-induced myocardial injury is not well understood, and the underlying mechanisms remain unclear. In the present study, 60 male Sprague Dawley rats were randomly divided into the following six groups: A sham group, cecal ligation and puncture (CLP) group, sham + propargylglycine (PAG) group, CLP+ PAG group, sham + sodium hydrosulfide (NaHS) group and CLP + NaHS group, with 10 rats in each group. The rats in all groups were sacrificed $12 \mathrm{~h}$ after surgery for sample collection. Compared with the sham group, it was observed that the concentrations of Creatine Kinase-MB (CK-MB) and cardiac troponin I (cTnI) in the serum, and pathological scores of myocardial tissue were significantly increased in the CLP, CLP + NaHS and CLP + PAG groups $(\mathrm{P}<0.05)$. The pathological scores and concentrations of CK-MB and cTnI were significantly higher in the CLP + PAG group $(\mathrm{P}<0.05)$ and significantly lower in the CLP + NaHS group $(\mathrm{P}<0.05)$ when compared with the CLP group. The expression of cystathionine- $\gamma$-lyase (CSE) mRNA and content of interleukin (IL)-10 were significantly higher in the CLP group compared with the CLP + PAG group $(\mathrm{P}<0.05)$, while the expression of myocardial $\mathrm{NF}-\kappa \mathrm{B}$ and content of tumor necrosis factor (TNF)- $\alpha$ in the CLP group were significantly lowered compared with the CLP + PAG group $(\mathrm{P}<0.05)$. The expression of $\mathrm{NF}-\kappa \mathrm{B}$ and content of
\end{abstract}

Correspondence to: Professor Qinghong Cheng, Department of Critical Care Medicine, First Affiliated Hospital, School of Medicine, Shihezi University, 32 North Second Road, Shihezi, Xinjiang 832003, P.R. China

E-mail: xunfeicheng@aliyun.com

Key words: hydrogen sulfide, sepsis, myocardial injury, nuclear factor- $\kappa \mathrm{B}$, tumor necrosis factor- $\alpha$
TNF- $\alpha$ were significantly increased in the CLP group when compared with the CLP + NaHS group $(\mathrm{P}<0.05)$, while the content of myocardial IL-10 in the CLP group was significantly lower than in the CLP + NaHS group $(\mathrm{P}<0.05)$. In conclusion, $\mathrm{H}_{2} \mathrm{~S}$ acted as an anti-inflammatory cytokine and biomarker in sepsis-induced myocardial injury. Furthermore, $\mathrm{H}_{2} \mathrm{~S}$ may downregulate the NF- $\kappa \mathrm{B}$ subunit $\mathrm{p} 65$ to mediate inflammatory responses. The present data suggest that myocardial injury in sepsis may be relieved through the regulation of $\mathrm{H}_{2} \mathrm{~S}$ expression, and provide an experimental basis for the treatment of sepsis patients presenting with myocardial injury. In addition, myocardial injury in sepsis may be identified by monitoring changes in the expression of $\mathrm{H}_{2} \mathrm{~S}$.

\section{Introduction}

Sepsis is a systemic inflammatory response syndrome caused by bacteria (or other microorganisms, including fungi), and is among the most serious complications of acute and critical illness (1). Sepsis may cause multiple organ damage and/or failure, and typically lead to acute lung injury (ALI), endothelial dysfunction, liver injury, blood coagulation dysfunction, bone marrow suppression, acid-base balance disorder and myocardial injury (2). Statistics show that $40-50 \%$ of patients with sepsis exhibit myocardial injury (3). The mechanism underlying the development of cardiac injury following sepsis is not well understood, though previous studies have indicated that inflammation serves a key role in sepsis $(4,5)$. The incidence of sepsis is increasing with a mortality rate of $\sim 30 \%$ each year in the USA (6). The terminal reason of death in severe sepsis patients is multiple organ dysfunction syndrome (MODS). Of patients with sepsis, 67\% exhibited MODS at sepsis recognition, with $30 \%$ subsequently developing new or progressive multi-organ dysfunction (7). Currently, the treatment of sepsis remains focused on early fluid resuscitation $(8,9)$. The effective prevention and management of myocardial injury during sepsis is an important part of treatment for sepsis (10).

Hydrogen sulfide $\left(\mathrm{H}_{2} \mathrm{~S}\right)$ is a poisonous gas (11). Endogenous $\mathrm{H}_{2} \mathrm{~S}$ is generated from cysteine; a reaction catalyzed by phosphotyrosine-5'-phosphate-dependent enzymes, including cystathionine- $\beta$-synthase (CBS), cystathionine- $\gamma$-lyase (CSE), and cysteine aminotransferase (12). CBS is highly expressed in the nervous system, while CSE is primarily expressed in vascular tissue and the myocardium (13). CSE is an important 
catalytic enzyme in the production of $\mathrm{H}_{2} \mathrm{~S}$ in myocardium, and it may be irreversibly blocked by propargylglycine (PAG), which may inhibit the production of $\mathrm{H}_{2} \mathrm{~S}$ in the body (14). However, a number of studies have revealed that $\mathrm{H}_{2} \mathrm{~S}$ serves an important roles in the physiology and pathophysiology of regulatory mechanisms as an important neurotransmitter molecule in cardiovascular regulation, and as a novel gaseous signal molecule, hepatic circulation regulatory molecule, oxygen sensor, inflammatory mediator, endothelium-derived relaxation factor and external factor in vasodilation and energy metabolism, particularly during inflammatory reactions $(15,16)$. Previous research has indicated that a low concentration of $\mathrm{H}_{2} \mathrm{~S}$ serves a protective effect in the regulation of tissues and inflammation during sepsis (17). Increasing the production of endogenous $\mathrm{H}_{2} \mathrm{~S}$, may also inhibit airway inflammation $(18,19)$. More recently, it has been observed that $\mathrm{H}_{2} \mathrm{~S}$ may suppress sepsis-induced ALI and reduce the inflammatory response during ALI (20). Furthermore, $\mathrm{H}_{2} \mathrm{~S}$ may inhibit the nuclear factor (NF)- $\mathrm{kB}$ signaling pathway $(21,22)$, and $\mathrm{H}_{2} \mathrm{~S}$ has been demonstrated to serve an important role in the regulation of NF- $\mathrm{KB}$ expression and activity (23). In a rat model of sepsis, Chen et al (24) observed that $\mathrm{H}_{2} \mathrm{~S}$ reduced kidney injury caused by urinary-derived sepsis by inhibiting $\mathrm{NF}-\kappa \mathrm{B}$ expression, decreasing tumor necrosis factor (TNF)- $\alpha$ levels and increasing interleukin (IL)-10 levels, thus indicating that $\mathrm{H}_{2} \mathrm{~S}$ serves an important role in inflammation and immune regulation during sepsis. However, there are few studies into the role of $\mathrm{H}_{2} \mathrm{~S}$ in sepsis-induced myocardial injury, and the underlying mechanism is not well understood. The present study aimed to evaluate the effect of endogenous and exogenous hydrogen sulfide in sepsis-induced myocardial injury in rats, and to explain the important regulatory role of $\mathrm{H}_{2} \mathrm{~S}$ in sepsis-induced myocardial injury.

\section{Materials and methods}

Drugs and reagents. Sodium hydrosulfide (NaHS) was purchased from Sigma-Aldrich (Merck KGaA, Darmstadt, Germany; cat. no. 1001915273). PAG was purchased from Sigma-Aldrich (Merck KGaA; cat. no. 101756193). Monoclonal antibody against the p65 subunit of NF- $\kappa B$ was purchased from Cell Signaling Technology, Inc. (Danvers, MA, USA; cat. no. 8242). Horseradish peroxidase-conjugated AffiniPure goat anti-rabbit immunoglobulin $\mathrm{G}(\mathrm{IgG})$ and anti- $\beta$-actin monoclonal antibody were purchased from ZSGB-BIO (ZSGB-Biotechnology Company Beijing, China; cat. nos. 8242ZB-2301 and TA-09, respectively). A Takara MiniBEST Universal RNA Extraction kit was purchased from Takara Bio, Inc. (Otsu, Japan; approval no. AK801). A Thermo Scientific $^{\text {TM }}$ Revert Aid ${ }^{\text {TM }}$ First Strand cDNA Synthesis kit was purchased from Thermo Fisher Scientific, Inc. (Waltham, MA, USA; approval no. K1622). Sequences of the polymerase chain reaction (PCR) primers, which were synthesized by Sangon Biotech Co., Ltd. (Shanghai, China) were as follows: For cystathionine- $\gamma$-lyase (CSE), forward, 5'-CCGATGACC TCAACGAACG-3' and reverse, 5'-GAGACGGTAGCC CAGGATAA-3' (national drugs approval nos. 8403261858 and 8403261859) and for $\beta$-actin, forward, 5'-CGTTGACAT CCGTAAAGACCTC-3' and reverse, 5'-TAGGAGCCAGGG CAGTAATCT-3' (national drug approval nos. 8403261860 and 8403261861). TNF- $\alpha$, IL-10 and cardiac troponin I (cTnI) ELISA detection kits were purchased from Beijing Cheng Lin Biotechnology Co., Ltd. (Beijing, China; cat. nos. E-30633, E-30649 and E-30308). Ketamine hydrochloride injection (Provided by First Affiliated Hospital, School of Medicine, Shihezi University) was purchased from Fujian Gutian Yuanhang Medical Co., Ltd. (Ningde, China; national drug approval no. H35020148). 2x GoldStar Best MasterMix (Dye) was purchased from Beijing ComWin Biotech Co., Ltd. (Beijing, China; cat. no. CW0655S).

Animals. A total of 60 adult male Sprague Dawley (SD) rats (7-8 week old, body weight, $227.34 \pm 19.81 \mathrm{~g}$ ) were obtained from the Animal Center of Xinjiang Medical University [Urumqi, China; animal use license: SYXK (Sinkiang) 2011-010101]. All experimental protocols in the present study conformed to the Guidelines for the Care and Use of Laboratory Animals published by the US National Institutes of Health (1996) and were approved by the Animal Care and Use Committee of Shihezi University (Shihezi, China). Animals were caged in groups of ten with free access to food and water and were maintained under a 12-h light/dark cycle at a room temperature of $22 \pm 1^{\circ} \mathrm{C}$ in a humidity of $45 \%$, and the rats were housed in normal air with $\mathrm{O}_{2} 21 \%, \mathrm{~N}_{2} 78 \%$ and $\mathrm{CO}_{2} 0.03 \%$. All experimental rats were anesthetized by intraperitoneally injecting $(5 \mathrm{mg} / 100 \mathrm{~g}$ body weight) of anesthetics containing ketamine $(40 \mathrm{mg} / \mathrm{kg})$ and xylazine $(10 \mathrm{mg} / \mathrm{kg})$ for cecal ligation and puncture (CLP), sham operation, or cervical dislocation.

Establishment of sepsis model. An experimental model of sepsis was reconstructed by cecal ligation and puncture (CLP). The rats were subjected to CLP as previously described $(25,26)$. The rats were anesthetized as described 5 mins prior to surgery. Briefly, under aseptic conditions, a $3-\mathrm{cm}$ midline laparotomy was performed to expose the cecum and adjoining intestine. The cecum was tightly ligated with a 2.0 -silk suture at its base, below the ileocecal valve, and was perforated twice with an 18-gauge needle. The cecum was then gently squeezed to extrude a small amount of feces from the puncture site. The cecum was returned to the peritoneal cavity and the laparotomy was closed with 3.0-silk sutures. Sham-operated animals underwent the same surgical procedure though the cecum was neither ligated nor punctured. Saline $(3 \mathrm{ml} / 100 \mathrm{~g})$ was administered to all rats intraperitoneally at the end of the procedure. All animals were returned to their cages with free access to food and water.

Experimental groups and protocol. The six groups of animals $(n=10$ per group) used in the present study were a sham-operated group (sham), which underwent a laparotomy; a sepsis group (CLP), which underwent CLP; a sepsis + PAG group $(C L P+P A G)$, which underwent an intraperitoneal injection of $50 \mathrm{mg} / \mathrm{kg}$ PAG $1 \mathrm{~h}$ after CLP, administered at $2 \mathrm{ml} / \mathrm{kg}$; a sepsis + NaHS group (CLP + NaHS), which underwent an intraperitoneal injection of $8.9 \mu \mathrm{mol} / \mathrm{kg}$ NaHS $1 \mathrm{~h}$ after CLP, administered at $2 \mathrm{ml} / \mathrm{kg}$; a sham-operated + PAG group (sham + PAG), which underwent an intraperitoneal injection of $50 \mathrm{mg} / \mathrm{kg}$ PAG $1 \mathrm{~h}$ after laparotomy, administered at $2 \mathrm{ml} / \mathrm{kg}$; and a sham-operated + NaHS group (sham + NaHS), which 
underwent an intraperitoneal injection of $8.9 \mu \mathrm{mol} / \mathrm{kg}$ NaHS $1 \mathrm{~h}$ after laparotomy, administered at $2 \mathrm{ml} / \mathrm{kg}$. The drug doses of PAG and NaHS and the administration method were derived from previous studies $(20,27,28)$. The rats were kept at a constant environmental temperature of $37^{\circ} \mathrm{C}$ to maintain body heat following the procedures. All rats were observed during this $12 \mathrm{~h}$ period for only 5 mins. At $12 \mathrm{~h}$ after laparotomy, the rats were re-anesthetized with the same dose of ketamine, and their abdomens were opened and $5 \mathrm{ml}$ blood was collected from the abdominal aorta. Following midline sternotomy, their hearts were removed, as previously described (29). After the specimens were collected, all rats (with the exception of 3 rats, which did not survive $12 \mathrm{~h}$, all of which succumbed to septic shock) were sacrificed by cervical dislocation. Plasma samples and hearts were immediately transferred to a biochemistry laboratory and stored in a refrigerator (DW-86L626; Qingdao Haier Special Electric Refrigerator Co., Ltd., Qingdao, China) at $-80^{\circ} \mathrm{C}$ for later determination of serum Creatine Kinase-MB (CK-MB) and cTnI levels. A section of the left myocardial tissue was fixed in $10 \%$ formalin solution for histomorphological analysis. A left myocardial tissue section was also used to determine the levels of TNF- $\alpha$ and IL-10, and to detect the expressions of $\mathrm{NF}-\kappa \mathrm{B}$ and CSE mRNA in the myocardial tissue.

Measurement of serum $C K-M B$ and cTnI levels. In order to assess plasma samples, serum was collected from the blood samples using a 2-16K High Speed Refrigerated Centrifuge (Sigma-Aldrich; Merck KGaA) after centrifugation (7,000 x g) for $15 \mathrm{~min}$ at $4^{\circ} \mathrm{C}$. Levels of CK-MB in the serum were measured using a Roche Modular DPP Automatic Biochemical Analyzer (Modular DPP H7600; Roche Diagnostics, Basel, Switzerland) by the inpatients department of the First Affiliated Hospital, Shihezi University. The CK-MB data were expressed in U/1. Levels of cTnI in the serum were quantified using a commercially available cTnI ELISA kit, according to the manufacturer's instructions. The cTnI results were expressed in $\mathrm{ng} / \mathrm{ml}$.

Histopathological examination. At $12 \mathrm{~h}$ post-surgery, the myocardial tissue of rats in different groups was collected and immediately washed twice with phosphate-buffered saline, then fixed in $10 \%$ neutral formalin at $25^{\circ} \mathrm{C}$ for $72 \mathrm{~h}$. The samples were successively dehydrated (Followed by soaking in 75,85 , 90, 95 and 95\% alcohol, anhydrous acetic acid, anhydrous ethanol and anhydrous ethanol, each for $30 \mathrm{~min}$ ) and paraffin embedded. Tissue sections $(4 \mu \mathrm{m})$ were then fixed in ethanol, as follows: Soaking in 70, 80 and $90 \%$ ethanol for 4-5 sec and then soaking in anhydrous ethanol for $5 \mathrm{~min}$ at room temperature. Sections were then stained with hematoxylin and eosin (H\&E) and analyzed and photographed using a light microscope (Olympus Corporation, Tokyo, Japan). The method by Rezkalla et al (30) was used to calculate pathological scores for the myocardial tissue sections.

Analysis of CSE mRNA expression in myocardial tissue by semiquantitative reverse transcription (RT)-PCR. The Takara MiniBEST Universal RNA Extraction kit was used to extract total RNA from the myocardial tissues, following the manufacturers protocol. Total RNA then served as a template to obtain cDNA by RT with a Thermo Scientific ${ }^{\mathrm{TM}}$ Revert Aid ${ }^{\mathrm{TM}}$ First Strand cDNA Synthesis kit. To analyze gene expression, the CSE cDNA was quantified and normalized using $\beta$-actin as a reference gene. For PCR, the $25 \mu \mathrm{l}$ PCR reaction system comprised $12.5 \mu \mathrm{l}$ Master Mix containing $\mathrm{KCl}, \mathrm{MgCl}$, Tris-HCl, dNTP and Taq DNA polymerase, $0.5 \mu 1$ forward primer, $0.5 \mu \mathrm{l}$ reverse primer, $3 \mu \mathrm{l}$ DNA template and $8.5 \mu \mathrm{l}$ nuclease-free distilled water. The reaction conditions were as follows: Initial denaturation at $95^{\circ} \mathrm{C}$ for $2 \mathrm{~min}, 35$ cycles at $94^{\circ} \mathrm{C}$ for $45 \mathrm{sec}, 95^{\circ} \mathrm{C}$ for $45 \mathrm{sec}, 58^{\circ} \mathrm{C}$ for $30 \mathrm{sec}$ and $72^{\circ} \mathrm{C}$ for $7 \mathrm{~min}$, followed by $72^{\circ} \mathrm{C}$ for a further $7 \mathrm{~min}$. A total of 35 cycles was used to produce satisfactory results. The PCR product was analyzed by electrophoresis in a $2 \%$ agarose gel, then placed in a Universal Hood II Systems for Gel Doc ${ }^{\mathrm{TM}}$ and ChemiDoc ${ }^{\mathrm{TM}}$ Imaging Systems (Model no. EN61000-6-1; Bio-Rad Laboratories Ltd., Hercules, CA, USA) for an absorbance scan. $\beta$-actin served as a reference for calibration, and the absorbance ratio of the target gene to that of $\beta$-actin was used to determine the relative level of target gene expression. Three replicates were performed. Following gel imaging, Quantity One image analysis software (version 4.6.9; Bio-Rad Laboratories, Inc., Hercules, CA, USA) was used to process the results. CSE mRNA and $\beta$-actin band expression were calculated as follows: band area $\mathrm{x}$ band average pixel values. Then the expression level of CSE mRNA was calculated as follows: CSE expression/ $\beta$-actin expression, and the relative content of target RNA was assessed. One-way ANOVA was used to analyze the statistical results.

Analysis of NF- $\kappa$ B expression in myocardial tissues by western blotting. Total protein was extracted from myocardial tissues using Radioimmunoprecipitation assay buffer (cat. no. R0010; Solarbio Science \& Technology Co., Ltd., Beijing, China) at a ratio of $10 \mathrm{mg}$ tissue to $100 \mu \mathrm{l}$ buffer, and protein concentration was determined using the bicinchoninic acid method (cat. no. P0012; Beyotime Institute of Biotechnology, Haimen, China). Equal amounts of myocardial protein $(25 \mathrm{mg} / \mathrm{lane})$ were separated on a 10\% SDS-PAGE gel and transferred onto $0.2 \mathrm{~mm}$ nitrocellulose membranes. The nitrocellulose blots were blocked by incubation in tris-buffered saline with Tween-20 (TBST; 10 mM Tris- $\mathrm{HCl}, \mathrm{pH} 7.5 ; 150 \mathrm{mM} \mathrm{NaCl}$ and $0.1 \%$ Tween-20) containing $5 \%$ non-fat powdered milk for $1 \mathrm{~h}$. The samples were subsequently mixed with anti-NF- $\kappa \mathrm{B}$ p65 monoclonal antibody (1:200 dilution) or $\beta$-actin monoclonal antibody $(1: 1,000)$ and incubated at $4^{\circ} \mathrm{C}$ overnight. The blots were then washed five times with TBST for $15 \mathrm{~min}$. Blots were incubated with horseradish peroxidase-linked anti-rabbit IgG for $1 \mathrm{~h}$ at room temperature, then washed five times in TBST for $15 \mathrm{~min}$. A chemiluminescent peroxidase substrate (cat. no. 34094; Thermo Fisher Scientific, Inc.) was applied according to the manufacturer's instructions, and the membranes were exposed briefly to X-ray film. Protein expression was analyzed by Universal Hood II Systems for Gel Doc ${ }^{\mathrm{TM}}$ and ChemiDoc ${ }^{\mathrm{TM}}$ Imaging Systems (Model no. EN61000-6-1, Bio-Rad Laboratories Ltd). The optical density of each target protein band was assessed with Quantity One software (version 4.6.2; Bio-Rad Laboratories, Inc.) and normalized to the corresponding $\beta$-actin bands in the same sample. Three replicates were performed.

Statistical analysis. Experimental data were presented as the mean \pm standard error of the mean. SPSS 17.0 software (SPSS, 
Inc., Chicago, IL, USA) was used for statistical analysis. Normal distribution variables among different groups were compared using one-way analysis of variance and non-normal distribution variables were compared using a Wilcoxon rank-sum test. Enumeration data were analyzed using a $\chi^{2}$ test. $\mathrm{P}<0.05$ was considered to indicate statistically significant results.

\section{Results}

Comparison of sepsis severity in model rats. The rats in the CLP group gradually appeared less active, were cold, had dull and upright fur, and stopped drinking water up to $6 \mathrm{~h}$ after the CLP procedure. Dyspnea occurred in 3 rats. In addition, 5 rats were in a passive supine position and responded slowly. Following the production of the model, the rats were placed in an animal room and observed by two researchers. There were 7 observation points: before modeling, 2, 4, 6, 8,10 and $12 \mathrm{~h}$ after modeling, at which rats were observed for 5 mins. The within $12 \mathrm{~h}$ mortality rate of the CLP group and the CLP + PAG group were $10 \%(n=9)$ and $20 \%(n=8)$, respectively, and the mortality rates of the sham group and the CLP + NaHS group were $0 \%$. The rats in the sham group were eating and exercising normally, in which had no anorectic and vertical hair. Rats in the CLP + NaHS group appeared anorectic, had vertical hair, and compared with the CLP group, rats in the CLP + NaHS group were less or completely inactive. Compared with the CLP + NaHS group, the symptoms (anorectic, vertical hair and reduced activity) were less severe than in the CLP group. Rats in the CLP + PAG group exhibited similar behavior to those in the CLP group. A comparison of the 12-h mortality rates of rats in each group is presented in Table I.

Pathological changes in the myocardial tissue of model rats. Pathological scores were calculated from the H\&E stained myocardial tissues of rats in each group (Fig. 1 and Table II). In the CLP group, the pathological score was significantly higher than that in the sham group $(\mathrm{P}<0.05)$. No significant differences were observed in the pathological scores of the sham, sham + PAG and sham + NaHS groups $(\mathrm{P}>0.05)$. The pathological score of the CLP group was significantly higher than that in the CLP + NaHS group $(\mathrm{P}<0.05)$, and significantly lower than that in the CLP + PAG group $(\mathrm{P}<0.05)$.

Changes in the serum levels of CK-MB and cTnI. As depicted in Fig. 2, the CLP, CLP + NaHS and CLP + PAG groups exhibited significantly higher levels of CK-MB and cTnI in the serum when compared with the sham group $(\mathrm{P}<0.05)$. The serum levels of CK-MB and cTnI did not differ significantly between the sham, sham + PAG and sham + NaHS groups $(\mathrm{P}>0.05)$. The serum levels of CK-MB and cTnI in the CLP group were significantly higher than that in the CLP + NaHS group $(\mathrm{P}<0.05)$, and significantly lower than that in the CLP + PAG group $(\mathrm{P}<0.05$; Fig. 2$)$.

Changes in TNF- $\alpha$ and IL-10 levels in the myocardial tissue of model rats. As depicted in Fig. 3, the CLP, CLP + NaHS and CLP + PAG groups exhibited significantly higher levels of TNF- $\alpha$ and IL-10 in the myocardial tissue when compared with the sham group $(\mathrm{P}<0.05)$. The levels of myocardial
Table I. Comparison of 12-h mortality rates of rats in each group.

\begin{tabular}{lc}
\hline Groups & Mortality rate, $\%$ \\
\hline Sham & 0 \\
Sham + NaHS & 0 \\
Sham + PAG & 0 \\
CLP & 10 \\
CLP + NaHS & 0 \\
CLP + PAG & 20 \\
\hline
\end{tabular}

CLP, cecal ligation and puncture; NaHS, sodium hydrosulfide; PAG, propargylglycine.

Table II. Pathological scoring of myocardial tissue determined by hematoxylin and eosin staining.

\begin{tabular}{lcc}
\hline Group & Case, $\mathrm{n}$ & Pathological score \\
\hline Sham & 10 & $236.16 \pm 38.88$ \\
Sham + NaHS & 10 & $248.92 \pm 83.35$ \\
Sham + PAG & 10 & $217.28 \pm 37.01$ \\
CLP & 9 & $796.91 \pm 89.57^{\mathrm{a}}$ \\
CLP + NaHS & 10 & $516.14 \pm 79.77^{\mathrm{a}, \mathrm{b}}$ \\
CLP + PAG & 8 & $1,016.14 \pm 79.77^{\mathrm{a}-\mathrm{c}}$ \\
\hline
\end{tabular}

Data are presented as the mean \pm standard error. ${ }^{\text {a }}<0.05$ vs. sham group, ${ }^{\mathrm{b}} \mathrm{P}<0.05$ vs. CLP group and ${ }^{\mathrm{c}} \mathrm{P}<0.05$ vs. CLP $+\mathrm{NaHS}$ group. CLP, cecal ligation and puncture; NaHS, sodium hydrosulfide; PAG, propargylglycine.

TNF- $\alpha$ and IL-10 did not differ significantly between the sham, sham + PAG and sham + NaHS groups $(\mathrm{P}>0.05)$. The levels of TNF- $\alpha$ in the CLP group were significantly higher than that in CLP + NaHS group $(\mathrm{P}<0.05)$, and significantly lower than that in the CLP + PAG group $(\mathrm{P}<0.05)$. The levels of IL-10 in the CLP group were significantly lower than that in the CLP + NaHS group $(\mathrm{P}<0.05)$, and significantly higher than that in the CLP + PAG group $(\mathrm{P}<0.05$, Fig. 3$)$. The current experimental design was to study the effect of endogenous and exogenous hydrogen sulfide on myocardial injury induced by sepsis, therefore the NaHS groups were not assayed for the expression of CSE mRNA.

Changes in CSE mRNA expression in the myocardial tissue of model rats. In the CLP group and the CLP + PAG group, the expression of CSE mRNA in the myocardial tissue was significantly increased compared with that in the sham group $(\mathrm{P}<0.05)$. The levels of CSE mRNA did not differ significantly between the sham and sham + PAG groups $(\mathrm{P}>0.05)$. Compared with the CLP group, the expression of CSE mRNA was significantly reduced in the CLP + PAG group $(\mathrm{P}<0.05$; Fig. 4).

Changes in NF- $\kappa$ B expression in the myocardial tissue of model rats. Results of western blot analysis (Figs. 5 and 6) indicated 

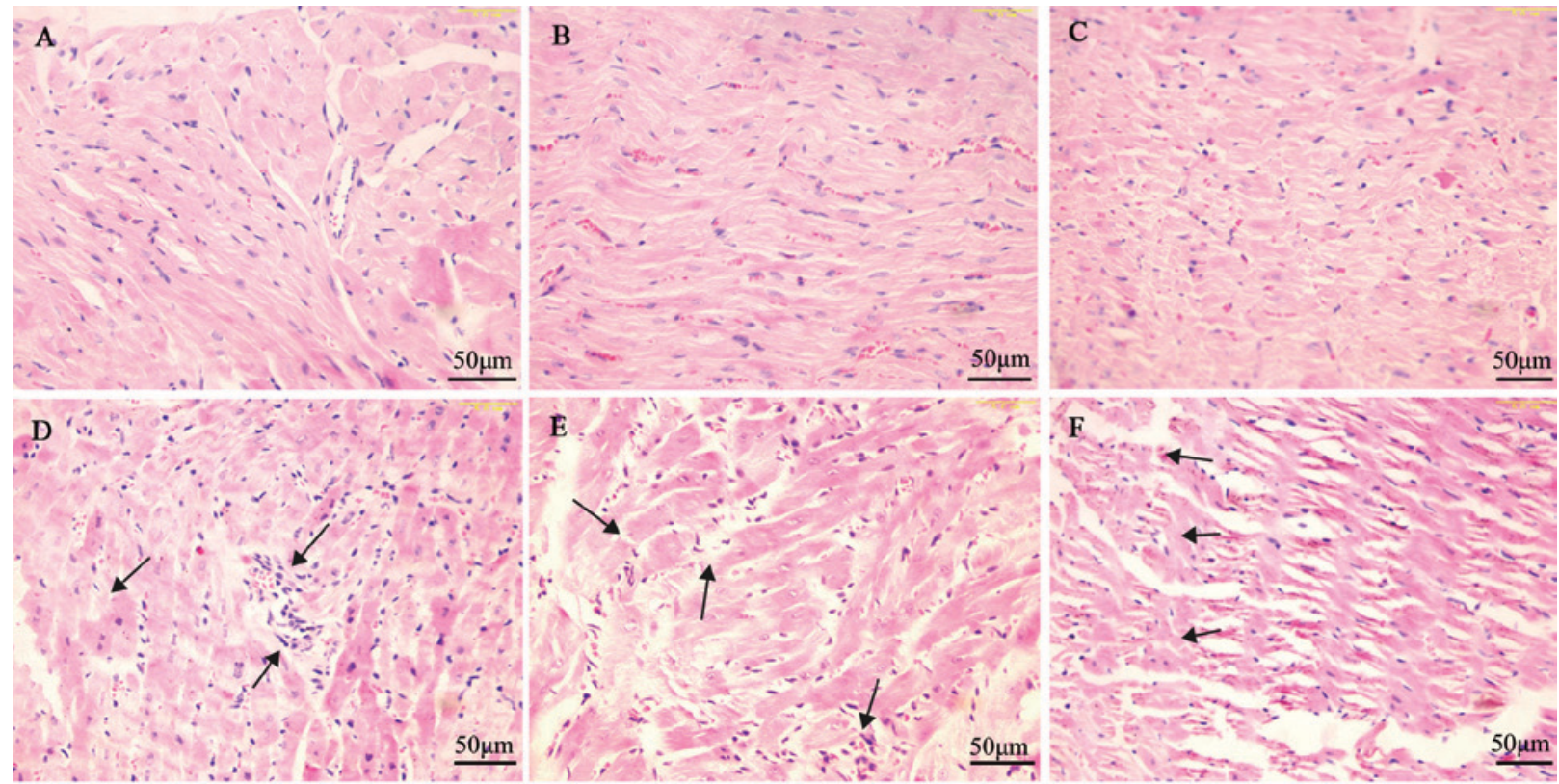

Figure 1. Examination of myocardial tissue pathology by hematoxylin and eosin staining. (A) Sham group, in which rats underwent a laparotomy; (B) sham + NaHS group, in which sham rats were treated with $8.9 \mu \mathrm{mol} / \mathrm{kg}$ NaHS $1 \mathrm{~h}$ after laparotomy; (C) sham + PAG group, in which sham rats were treated with $50 \mathrm{mg} / \mathrm{kg}$ PAG $1 \mathrm{~h}$ after laparotomy; (D) CLP group, in which rats underwent CLP; (E) CLP + NaHS group, in which CLP rats were treated with $8.9 \mu \mathrm{mol} / \mathrm{kg}$ NaHS $1 \mathrm{~h}$ after CLP; (F) CLP + PAG group, in which CLP rats were treated with $50 \mathrm{mg} / \mathrm{kg}$ PAG $1 \mathrm{~h}$ after CLP. Magnification, x200. CLP, cecal ligation and puncture; NaHS, sodium hydrosulfide; PAG, propargylglycine.
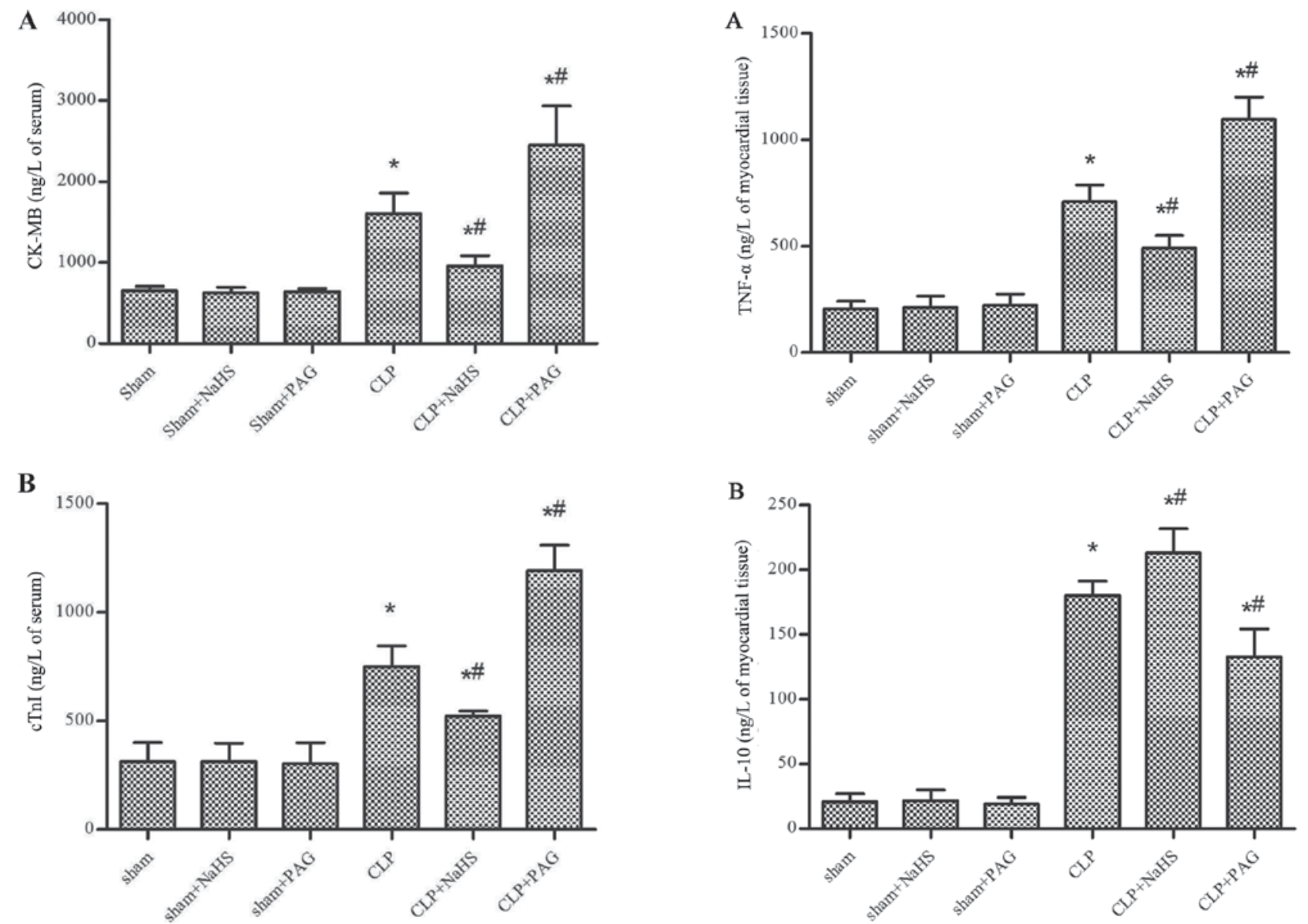

Figure 2. Change in the serum levels of (A) CK-MB and (B) cTnI in sepsis rats. Data are presented as the mean \pm standard error of the mean. ${ }^{*} \mathrm{P}<0.05$ vs. sham group; " $\mathrm{P}<0.05$ vs. CLP group. CK-MB, Creatine Kinase-MB; cTnI, cardiac troponin I; CLP, cecal ligation and puncture; NaHS, sodium hydrosulfide; PAG, propargylglycine.

Figure. 3. Change in the myocardial tissue levels of (A) TNF- $\alpha$ and (B) IL-10 in sepsis rats. Data are presented as the mean \pm standard error of the mean. ${ }^{*} \mathrm{P}<0.05$ vs. sham group; ${ }^{*} \mathrm{P}<0.05$ vs. CLP group. TNF, tumor necrosis factor; IL, interleukin; CLP, cecal ligation and puncture; NaHS, sodium hydrosulfide; PAG, propargylglycine. 

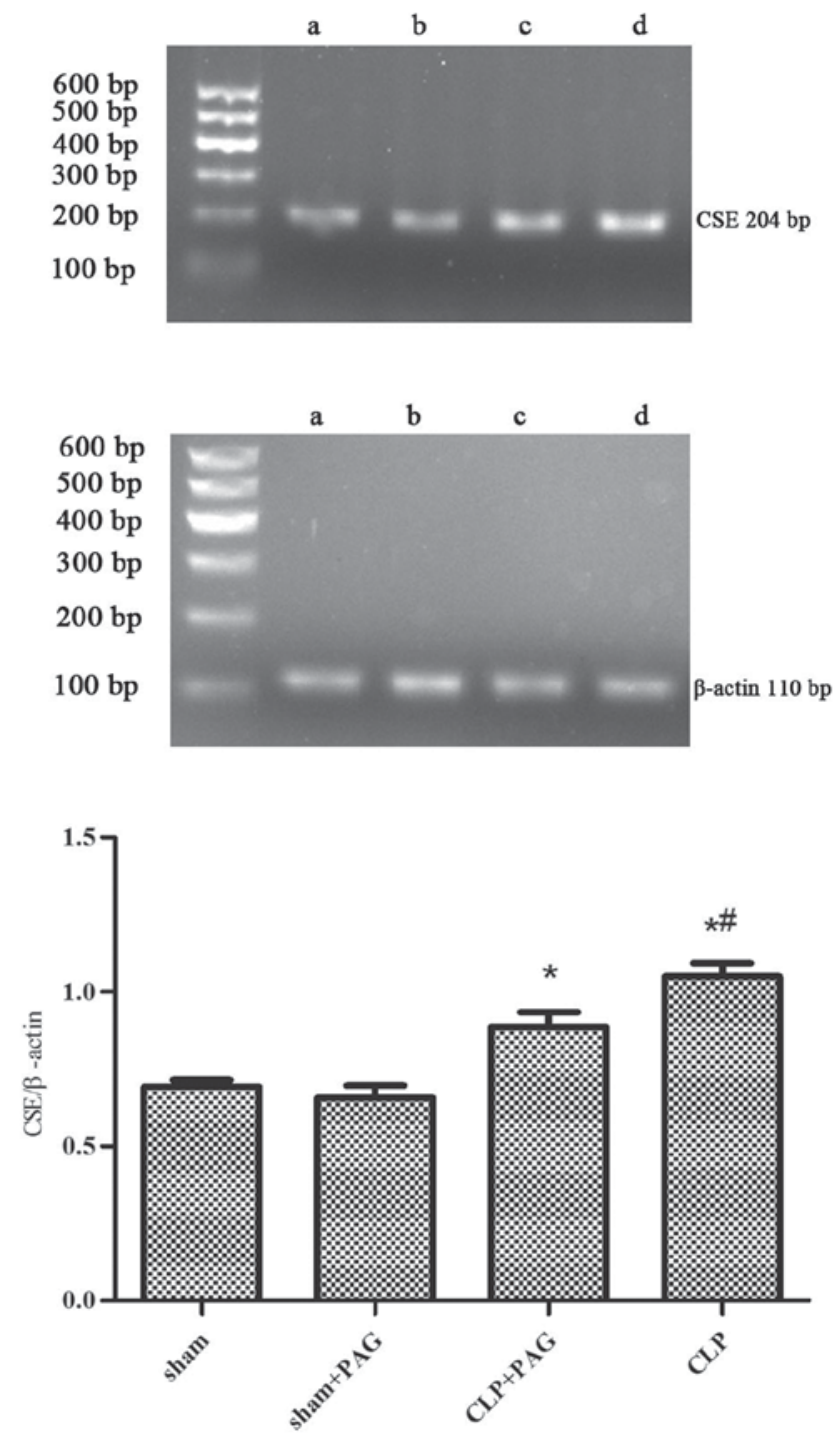

Figure 4. Analysis of CSE mRNA expression in the myocardial tissue of sepsis rats by reverse transcription-polymerase chain reaction. Lanes a, b, $c$ and d show results of the sham, sham + PAG, CLP + PAG and CLP groups, respectively. ${ }^{*} \mathrm{P}<0.05$ vs. sham group; ${ }^{\text {P }}<0.05$ vs. $C L P+P A G$ group. CSE, cystathionine- $\gamma$-lyase; CLP, cecal ligation and puncture; PAG, propargylglycine.

that the expression of $N F-\kappa B$ was significantly increased in the CLP group, the CLP + PAG group and the CLP + NaHS group when compared with the sham group $(\mathrm{P}<0.05)$. NF- $\kappa \mathrm{B}$ expression in the myocardial tissue did not differ significantly between the sham and sham + PAG groups ( $\mathrm{P}>0.05$; Fig. 5), or between the sham and sham + NaHS groups ( $P>0.05$; Fig. 6). Compared with the CLP group, the expression of NF- $\kappa \mathrm{B}$ was significantly increased in the CLP + PAG group $(\mathrm{P}<0.05$; Fig. 5) and significantly decreased in the CLP + NaHS group $(\mathrm{P}<0.05$; Fig. 6).

\section{Discussion}

$\mathrm{H}_{2} \mathrm{~S}$ was initially considered to exert toxic effects on the human body (6). However, more recently, studies have indicated that $\mathrm{H}_{2} \mathrm{~S}$ is an important anti-inflammatory mediator in vivo $(31,32)$, and physiological concentrations of $\mathrm{H}_{2} \mathrm{~S}$ have been demonstrated to serve key roles in the regulation of
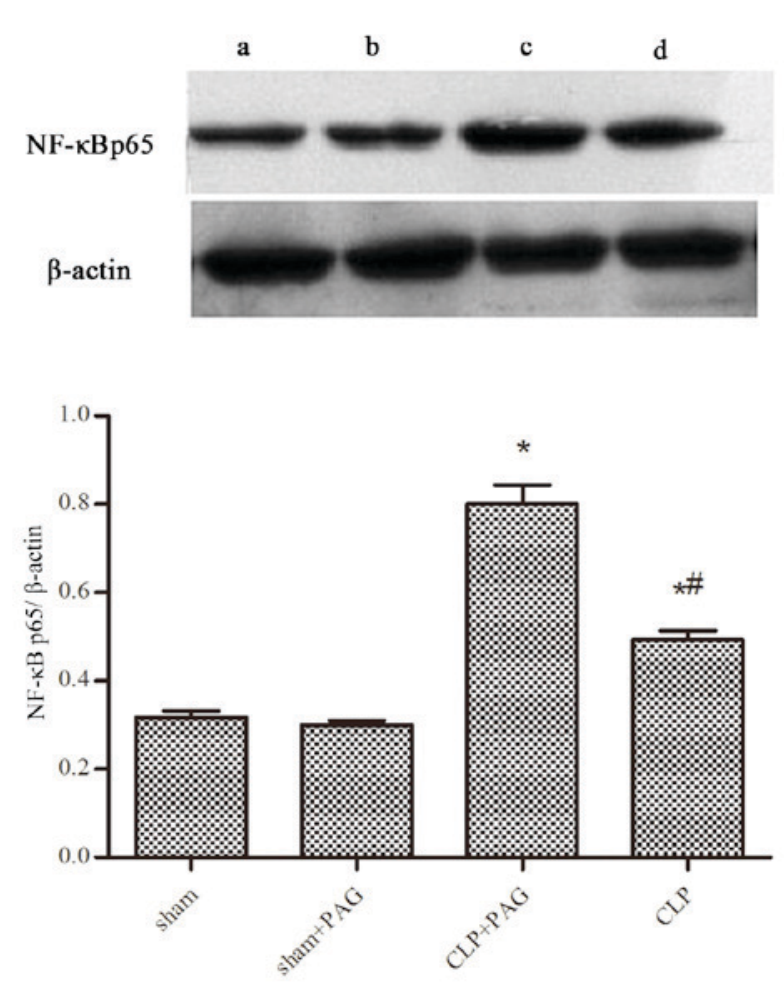

Figure 5. Change in the expression of NF- $\mathrm{kB}$ p 65 in the myocardial tissue of sepsis rats following treatment with PAG. Lanes a, b, c and d show results of the sham, sham + PAG, CLP + PAG and CLP groups, respectively. ${ }^{*}<0.05$

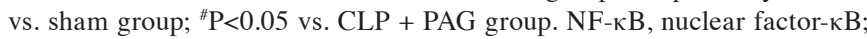
CLP, cecal ligation and puncture; PAG, propargylglycine.

inflammation during sepsis (33). Endogenous $\mathrm{H}_{2} \mathrm{~S}$ is generated from cysteine; a reaction catalyzed by phosphotyrosine-5'-phosphate-dependent enzymes, including cystathionine- $\beta$-synthase (CBS), cystathionine- $\gamma$-lyase (CSE), and cysteine aminotransferase (12). CBS is highly expressed in the nervous system, while CSE is mainly expressed in vascular tissue and the myocardium (13). CSE may be irreversibly blocked by PAG, which can inhibit the production of $\mathrm{H}_{2} \mathrm{~S}$ in the body (14). A third of the total $\mathrm{H}_{2} \mathrm{~S}$ in the body is present in gaseous form, while two-thirds exist as $\mathrm{HS}^{-}$. A balance between NaHS and $\mathrm{HS}^{-}$exists to ensure the presence of $\mathrm{H}_{2} \mathrm{~S}$ and maintain a stable $\mathrm{pH}$ environment (34). Under physiological conditions, the plasma level of $\mathrm{H}_{2} \mathrm{~S}$ has been recorded at $\sim 46 \mu \mathrm{mol} / 1$ in SD rats (35). The properties of NaHS are stable and its concentration in solution may be controlled, and thus it is often used in experiments. Therefore, the drug was used in the present study as a donor of $\mathrm{H}_{2} \mathrm{~S}$.

Sepsis, when combined with myocardial injury, may aggravate its own development and increase the risk of multiple organ failure and mortality (36). Despite extensive study into sepsis-induced myocardial damage, the underlying mechanism is not well understood, though potentially involves myocardial ischemia-reperfusion injury, circulating myocardium inhibitory factor, mitochondrial dysfunction and oxidative stress injury (37). Elucidating the underlying mechanisms of myocardial injury in sepsis, and methods to prevent damage to heart function during early-stage sepsis, have been the focus of medical research. In the current study, a rat model of sepsis was established by CLP, which successfully induced the symptoms and signs of sepsis. Indeed, CLP is considered to 

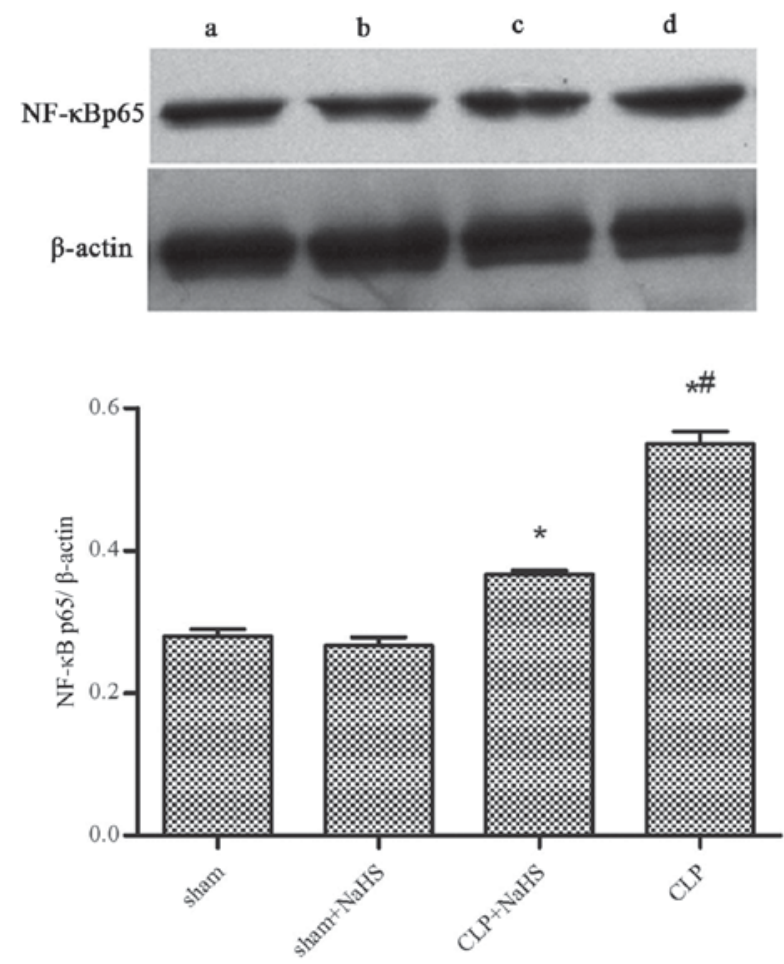

Figure 6. Change in the expression of NF-kB p65 in the myocardial tissue of sepsis rats following treatment with NaHS. Lanes a, b, c and d show results of the sham, sham + NaHS, CLP + NaHS and CLP groups, respectively. ${ }^{*}<0.05$

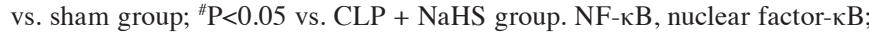
CLP, cecal ligation and puncture; NaHS, sodium hydrosulfide.

be a gold standard sepsis model (28). Male SD rats of similar age were also used in the current study to avoid the potential effects of gender, age, hormone levels and other factors on the results.

Analysis of myocardial markers demonstrated that the serum concentrations of CK-MB and CTnI were increased in rats subjected to CLP, with the highest levels observed in CLP + NaHS group, followed by the CLP and CLP + PAG groups (in successive order). The greatest injury to the myocardial tissue was observed in the CLP + PAG group, followed by the CLP, CLP + NaHS and sham groups (in successive order). These results suggested that inhibition of endogenous $\mathrm{H}_{2} \mathrm{~S}$ expression may aggravate myocardial injury during sepsis, while exogenous $\mathrm{H}_{2} \mathrm{~S}$ may alleviate myocardial injury induced by sepsis in rats. Therefore, $\mathrm{H}_{2} \mathrm{~S}$ may alleviate myocardial injury and exert protective effects on myocardial tissue during sepsis.

$\mathrm{NF}-\kappa \mathrm{B}$, as a key nuclear transcription factor, is widely expressed in eukaryotic cells and is a member of the Rel protein family $(38,39)$. At present, 5 members of this family have been identified in mammals; p65 (RelA), RelB, C-Rel,

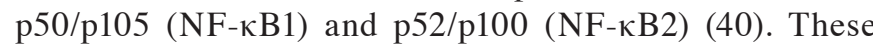
proteins are typically present as homo- or heterodimers. p65 is the main subunit of the NF- $\mathrm{KBp50/p65} \mathrm{dimer,} \mathrm{which} \mathrm{serves}$ major roles in physiological processes (40). In particular, studies have indicated that NF- $\mathrm{NB}$ serves an important role in the generation and release of inflammatory mediators and cytokines $(41,42)$. TNF- $\alpha$ also acts as a dynamic factor within intracellular cascades. TNF- $\alpha$ may induce the degradation of $N F-\kappa B$ inhibitor $(\mathrm{I} \kappa \mathrm{B})$ and thus enhance NF- $\mathrm{NB}$ activity to promote the synthesis and release of TNF- $\alpha$, IL- 1 and IL-6, which forms a cascade reaction (43). A previous study documented that the expression of proinflammatory cytokines was increased in patients with sepsis, while the expression of anti-inflammatory cytokines was decreased, which was associated with poor prognosis (44). Therefore, the condition of patients with sepsis may be improved by reducing the levels of IL-6, IL-8 and IL-1 and increasing the levels of IL-10.

In the present study, increased expressions of $\mathrm{NF}-\kappa \mathrm{B}$ and TNF- $\alpha$ in the myocardial tissue of the CLP group were accompanied by an increased pathological score and concentration of cTnI, while the concentration of IL-10 appeared to be inversely associated with myocardial pathological score and cTnI concentration. This may have been due to the inhibition of $\mathrm{NF}-\kappa \mathrm{B}$ expression by $\mathrm{H}_{2} \mathrm{~S}$, as active $\mathrm{NF}-\kappa \mathrm{B}$ downregulates the expression of proinflammatory cytokines, including TNF- $\alpha$, and upregulates the expression of the anti-inflammatory factor IL-10 (24).

The expression of CSE mRNA was significantly higher in the CLP group when compared with the CLP + PAG group. Furthermore, the expression of CSE mRNA was significantly higher in the CLP + PAG group when compared with the sham and sham + PAG groups, indicating that myocardial CSE expression was significantly inhibited in the sepsis model, which may have reduced the production of $\mathrm{H}_{2} \mathrm{~S}$ in the myocardial tissue. The expressions of NF- $\kappa \mathrm{B}$ and TNF- $\alpha$ in the CLP group were significantly lower than that in the CLP + PAG group, and the expression of IL-10 in the CLP group was significantly higher than that in the CLP + PAG group. In addition, the level of IL-10 in the CLP group was significantly lower than that in the CLP + NaHS group. Li et al (45) observed that $\mathrm{H}_{2} \mathrm{~S}$ may reduce the level of serum TNF- $\alpha$, increase the level of IL-10, and attenuate the inflammatory response and tissue damage in an early model of acute abdominal infection in rats; while reduced levels of $\mathrm{H}_{2} \mathrm{~S}$ may increase the inflammatory response. Ma et al (44) reported that TNF- $\alpha$ may induce I $\kappa$ B degradation, enhance NF- $\kappa$ B activity and promote the synthesis and release of TNF- $\alpha$, IL-1, IL-6 in neutrophils to form a cascade reaction. $\mathrm{H}_{2} \mathrm{~S}$ has been documented to exert an inhibitory effect on cytokine production and inflammatory cell chemotaxis in the early stage of sepsis, which inhibits the inflammatory reaction and inflammatory cascades, thus protecting the tissue (45). In a myocardial ischemia model, Liu et al (46) observed that the protective effect of NaHS on myocardial tissues was associated with its modulation of inflammatory factors and anti-inflammatory effects. Chen et al (24) also documented that exogenous $\mathrm{H}_{2} \mathrm{~S}$ may inhibit NF- $\mathrm{B}$ expression in a rat model of sepsis, which may subsequently downregulate IL-10 and upregulate TNF- $\alpha$, thereby reducing sepsis-induced renal injury. These results indicate that reduced production of endogenous $\mathrm{H}_{2} \mathrm{~S}$ in a rat model of sepsis may increase the expressions of $\mathrm{NF}-\kappa \mathrm{B}$ and TNF- $\alpha$ and decrease the expression of IL-10 in myocardial tissue, which in turn may aggravate sepsis-induced myocardial injury. Therefore, administration of exogenous $\mathrm{H}_{2} \mathrm{~S}$ may attenuate sepsis-induced myocardial injury by downregulating $\mathrm{NF}-\kappa \mathrm{B}$ and the proinflammatory cytokine TNF- $\alpha$ and upregulating the anti-inflammatory factor IL-10.

In conclusion, $\mathrm{H}_{2} \mathrm{~S}$ may be involved in the pathogenesis of sepsis and may serve a protective role in sepsis-induced 
myocardial injury. Its underlying mechanism of action may involve the inhibition of NF- $\mathrm{KB}$ expression, downregulation of the proinflammatory factor TNF- $\alpha$ and upregulation of the anti-inflammatory factor IL-10. The present data indicate that myocardial injury during sepsis may be relieved through the regulation of $\mathrm{H}_{2} \mathrm{~S}$ expression, and thus provide an experimental basis for the treatment of patients with sepsis-induced myocardial injury.

\section{Acknowledgements}

The present study was supported by the College Scientific Research Project of Shihezi University, China (grant no. YL2016-R003) and the Project of Corps Science and Technology Research and Achievement Transformation Project, China (grant no. 2016AD003). The present study was also supported by the Laboratory of Xinjiang Endemic and Ethnic Diseases. The authors would like to thank Professor Dawei Liu (Peking Union Medical College, Tsinghua University, Beijing, China) for his assistance with the statistical analysis.

\section{References}

1. Angus DC, Linde-Zwirble WT, Lidicker J, Clermont G, Carcillo J and Pinsky MR: Epidemiology of severe sepsis in the United States: Analysis of incidence, outcome and associated costs of care. Crit Care Med 29: 1303-1310, 2001.

2. Esper AM and Martin GS: Extending international sepsis epidemiology: The impact of organ dysfunction. Crit Care 13: 120, 2009.

3. Turner A, Tsamitros M and Bellomo R: Myocardial cell injury in septic shock. Crit Care Med 27: 1775-1780, 1999.

4. Y-Hassan S, Settergren M and Henareh L: Sepsis-induced myocardial depression and takotsubo syndrome. Acute Card Care 16: 102-109, 2014.

5. Antonucci E, Fiaccadori E, Donadello K, Taccone FS, Franchi F and Scolletta S: Myocardial depression in sepsis: From pathogenesis to clinical manifestations and treatment. J Crit Care 29: 500-511, 2014.

6. Ani C, Farshidpanah S, Bellinghausen Stewart A and Nguyen HB: Variations in organism-specific severe sepsis mortality in the United States: 1999-2008. Crit Care Med 43: 65-77, 2015.

7. Weiss SL, Fitzgerald JC, Pappachan J, Wheeler D, Jaramillo-Bustamante JC, Salloo A, Singhi SC, Erickson S, Roy JA, Bush JL, et al: Global epidemiology of pediatric severe sepsis: The sepsis prevalence, outcomes, and therapies study. Am J Respir Crit Care Med 191: 1147-1157, 2015.

8. ProCESS Investigators, Yealy DM, Kellum JA, Huang DT, Barnato AE, Weissfeld LA, Pike F, Terndrup T, Wang HE, Hou PC, et al: A randomized trial of protocol-based care for early septic shock. N Engl J Med 370: 1683-1693, 2014.

9. Jiang LB, Zhang M, Jiang SY and Ma YF: Early goal directed resuscitation for patients with severe sepsis and septic shock: A meta-analysis and trial sequential analysis. Scand J Trauma Resusc Emerg Med 24: 23, 2016.

10. Krishnagopalan S, Kumar A, Parrillo JE and Kumar A: Myocardial dysfunction in the patient with sepsis. Curr Opin Crit Care 8: 376-388, 2002.

11. Beauchamp RO Jr, Bus JS, Popp JA, Boreiko CJ and Andjelkovich DA: A critical review of the literature on hydrogen sulfide toxicity. Crit Rev Toxicol 13: 25-97, 1984.

12. Abe $\mathrm{K}$ and Kimura $\mathrm{H}$ : The possible role of hydrogen sulfide as an endogenous neuromodulator. J Neurosei 16: 1066-1071, 1996.

13. Qipshidze N, Metreveli N, Mishra PK, Lominadze D and Tyagi SC: Hydrogen sulfide mitigates cardiac remodeling during myocardial infarction via improvement of angiogenesis. Int J Biol Sci 8: 430-441, 2012.

14. Zhao W, Ndisang JF and Wang R: Modulation of endogenous product of $\mathrm{H} 2 \mathrm{~S}$ in rat tissues. Can J Physiol Pharmacol 81: 848-853, 2003.

15. Sowmya S, Swathi Y, Yeo AL, Shoon ML, Moore PK and Bhatia M: Hydrogen sulfide: Regulatory role on blood pressure in hyperhomocysteinemia. Vascul Pharmacol 53: 138-143, 2010.
16. Tamizhselvi R, Moore PK and Bhatia M: Inhibition of hydrogen sulfide synthesis attenuates chemokine production and protects mice against acute pancreatitis and associated lung injury. Pancreas 36: e24-e31, 2008.

17. Whiteman $M$ and Winyard PG: Hydrogen sulfide and inflammation: The good, the bad, the ugly and the promising. Expert Rev Clin Pharmacol 4: 13-32, 2011.

18. Tokuda K, Kida K, Marutani E, Crimi E, Bougaki M, Khatri A, Kimura $\mathrm{H}$ and Ichinose F: Inhaled hydrogen sulfide prevents endotoxin-induced systemic inflammation and improves survival by altering sulfide metabolism in mice. Antioxid Redox Signal 17: 11-21, 2012.

19. Chen YH, Wu R, Geng B, Qi YF, Wang PP, Yao WZ and Tang CS: Endogenous hydrogen sulfide reduces airway inflammation and remodeling in a rat model of asthma. Cytokine 45: 117-123, 2009.

20. Ang SF, Sio SW, Moochhala SM, MacAry PA and Bhatia M: Hydrogen sulfide upregulates cyclooxygenase-2 and prostaglandin E metabolite in sepsis-evoked acute lung injury via transient receptor potential vanilloid type 1 channel activation. J Immunol 187: 4778-4787, 2011.

21. Chattopadhyay M, Kodela R, Nath N, Barsegian A, Boring D and Kashfi K: Hydrogen sulfide-releasing aspirin suppresses NF- $\mathrm{B}$ signaling in estrogen receptor negative breast cancer cells in vitro and in vivo. Biochem Pharmacol 83: 723-732, 2012.

22. Yang C, Yang Z, Zhang M, Dong Q, Wang X, Lan A, Zeng F, Chen P, Wang $C$ and Feng J: Hydrogen sulfide protects against chemical hypoxia-induced cytotoxicity and inflammation in $\mathrm{HaCaT}$ cells through inhibition of $\mathrm{ROS} / \mathrm{NF}-\kappa \mathrm{B} / \mathrm{COX}-2$ pathway. PLoS One 6: e21971, 2011.

23. Sen N, Paul BD, Gadalla MM, Mustafa AK, Sen T, Xu R, Kim S and Snyder SH: Hydrogen sulfide-linked sulfhydration of NF- $\kappa \mathrm{B}$ mediates its antiapoptotic actions. Mol Cell 45: 13-24, 2012.

24. Chen X, Xu W, Wang Y, Luo H, Quan S, Zhou J, Yang N, Zhang T, Wu L, Liu J, et al: Hydrogen sulfide reduces kidney injury due to urinary-derived sepsis by inhibiting NF- $\kappa \mathrm{B}$ expression, decreasing TNF- $\alpha$ levels and increasing IL-10 levels. Exp Ther Med 8: 464-470, 2014.

25. Wichterman KA, Baue AE and Chaudry IH: Sepsis and septic shock-a review of laboratory models and a proposal. J Surg Res 29: 189-201, 1980.

26. Otero-Antón E, González-Quintela A, López-Soto A López-Ben S, Llovo J and Pérez LF: Cecal ligation and puncture as a model of sepsis in the rat: Influence of the puncture size on mortality, bacteremia, endotoxemia and tumor necrosis factor alpha levels. Eur Surg Res 33: 77-79, 2001.

27. Collin M, Anuar FB, Murch O, Bhatia M, Moore PK and Thiemermann C: Inhibition of endogenous Hydrogen sulfide formation reduces the organ injury caused by endotoxemia. Br J Pharmacol 146: 498-505, 2005.

28. Rittirsch D, Huber-Lang MS, Flierl MA and Ward PA: Immunodesign of experimental sepsis by cecal ligation and puncture. Nat Protoc 4: 31-36, 2009.

29. Cabrera JA, Ziemba EA, Colbert R, Anderson LB, Sluiter W, Duncker DJ, Butterick TA, Sikora J, Ward HB, Kelly RF and McFalls EO: Altered expression of mitochondrial electron transport chain proteins and improved myocardial energetic state during late ischemic preconditioning. Am J Physiol Heart Circ Physiol 302: H1974-H1982, 2012.

30. Rezkalla S, Kloner RA, Khatib G, Smith FE and Khatib R: Effect of metoprolol in acute coxsackievirus B3 murine myocarditis. J Am Coll Cardiol 12: 412-414, 1988.

31. Sivarajah A, Collino M, Yasin M, Benetti E, Gallicchio M, Mazzon E, Cuzzocrea S, Fantozzi R and Thiemermann C: Anti-apoptotic and anti-inflammatory effects of hydrogen sulfide in a rat model of regional myocardial I/R. Shock 31: 267-274, 2009.

32. Hirata I, Naito Y, Takagi T, Mizushima K, Suzuki T, Omatsu T, Handa O, Ichikawa $\mathrm{H}$, Ueda $\mathrm{H}$ and Yoshikawa T: Endogenous hydrogen sulfide is an anti-inflammatory molecule in dextran sodium sulfate-induced colitis in mice. Dig Dis Sci 56: 1379-1386, 2011.

33. Zanardo RC, Brancaleone V, Distrutti E, Fiorucci S, Cirino G and Wallace JL: Hydrogen sulfide is an endogenous modulator of leukocyte mediated inflam-mation. FASEB J 20: 2118-2120, 2006.

34. Hosoki R, Matsuki $\mathrm{N}$ and Kimura $\mathrm{H}$ : The possible role of hydrogen sulfide as an endogenous smooth muscle relaxant in synergy with nitric oxide. Biochem Biophys Res Commun 237: 527-531, 1997.

35. Wang R: The gasotransmitter role of hydrogen sulfide. Antioxid Redox Signal 5: 493-501, 2003. 
36. Jeremias A and Gibson CM: Narrative review: Alternative causes for elevated cardiac troponin levels when acute coronary syndromes are excluded. Ann Intern Med 142: 786-791, 2005.

37. Y-Hassan S, Settergren M and Henareh L: Sepsis-induced myocardial depression and takotsubo syndrome. Acute Card Care 16: 102-109, 2014.

38. Ghosh S, May MJ and Kopp EB: NF-kappa B and Rel proteins: Evolutionarily conserved mediators of immune responses. Annu Rev Immunol 16: 225-260, 1998.

39. Baldwin AS Jr: Series introduction: The transcription factor NF-kappaB and human disease. J Clin Invest 107: 3-6, 2001.

40. Siebenlist U, Fronzoso G and Brown K: Structure regulation and function of NF-kappa B. Annu Rev Cell Biol 10: 405-455, 1994.

41. Schlegel N, Leweke R, Meir M, Germer CT and Waschke J: Role of NF- $\kappa \mathrm{B}$ activation in LPS-induced endothelial barrier breakdown. Histochem Cell Biol 138: 627-641, 2012.
42. Cheng CC, Chen YH, Chang WL, Yang SP, Chang DM, Lai JH and Ho LJ: Phytoestrogen bavachin mediates anti-inflammation targeting Ikappa B kinase-I kappaB alpha-NF-kappaB signaling pathway in chondrocytes in vitro. Eur J Pharmacol 636: 181-188, 2010.

43. Schütze S, Wiegmann K, Machleidt T, Krönke M: TNF-induced activation of NF-kappa B. Immunobiology 193: 193-203, 1995.

44. Ma X, Chang W, Zhang C, Zhou X and Yu F: Staphylococcal Panton-Valentine leukocidin induces pro-inflammatory cytokine production and nuclear factor-kappa B activation in neutrophils. PLoS One 7: e34970, 2012.

45. Li H, Liu H, Wang D, Li GS and Cao YX: The role of hydrogen sulfide in prophase of acute peritoneal cavity infection of rat. Chin J Bases Clinics General Surg 19: 277-281, 2012 (In Chinese).

46. Liu F, Liu GJ, Liu N, Zhang G, Zhang JX and Li LF: Effect of hydrogen sulfide on inflammatory cytokines in acute myocardial ischemia injury in rats. Exp Ther Med 9: 1068-1074, 2015. 